\title{
Do armário à armadura: estratégias de mulheres no enfrentamento da homofobia e do heterossexismo.
}

From the closet to the shield: women's strategies to fight against homophobia and heterosexism

Del armario a la armadura: estrategias de mujeres en el enfrentamiento de la homofobia y lo heterosexismo

\section{Luciana Fogaça Monteiro}

Universidade Federal do Rio Grande do Sul, Porto Alegre, RS, Brasil.

\section{Paula Sandrine Machado}

Universidade Federal do Rio Grande do Sul, Porto Alegre, RS, Brasil.

Henrique Caetano Nardi

Universidade Federal do Rio Grande do Sul, Porto Alegre, RS, Brasil.

\section{Resumo}

O objetivo do presente artigo é descrever e analisar as estratégias construídas por mulheres que buscaram o Centro de Referência em Direitos Humanos Rompa o Silêncio (Porto Alegre, RS) para lidar, enfrentar ou contestar os significados estigmatizantes associados a suas identidades de gênero ou práticas eróticas/afetos com outras mulheres. A ferramenta metodológica utilizada foi a entrevista baseada na reconstrução de trajetórias de vida e foram entrevistadas 9 mulheres que haviam acessado o Centro de Referência em 2007. As análises estão divididas em dois eixos temáticos: a) percepções sobre a homofobia na perspectiva das mulheres e b) estratégias de enfrentamento cotidianas e o sentido da busca pela formalização da denúncia e reivindicação de direitos. O material permitiu compreender que as entrevistadas percebem a discriminação e o preconceito como resultado de uma extrapolação dos limites das convenções de gênero. Nesse sentido, acreditam que a homossexualidade masculina e as mulheres que possuem estilos "mais masculinos" estão mais propensos/as a sofrer discriminações. De acordo com elas, a perspectiva de uma maior "aceitação" das relações homoeróticas entre mulheres ocorre na articulação entre estilos mais próximos dos padrões de feminilidade vigentes, bem como por uma apropriação do homoerotismo feminino por parte do fetiche masculino. Quanto às estratégias de enfrentamento, foram encontradas tanto formas de manter identidades "discretas" como modos mais combativos, baseados em uma "subjetivação militante". De modo geral, as entrevistadas consideram os tempos atuais 
melhores, devido, segundo elas, mais à atuação do movimento social do que aos aparelhos de proteção e políticas públicas estatais.

Palavras-chave: Homofobia, Lesbofobia, Mulheres, Direitos Humanos, Brasil Sem Homofobia.

\begin{abstract}
This article's goal is to describe and analyze the strategies constructed by women that searched for Human Rights Reference Center "Rompa o silêncio" (Porto Alegre, RS) in order to deal, confront or contest stigmatizing representations associated to their gender identities or erotic practices/affections with other women. The methodological tool used was based on life trajectories interviews and 9 women that accessed the Reference Center in 2007. Analysis is divided in two thematic axes: a) homophobia perception in women's point of view; b) Quotidian coping strategies and attributed meanings for formalizing plaints and rights vindication. The research material allowed understanding that the interviewees comprehend discrimination and prejudice as the result of gender conventions' extrapolation. In this sense, they believe that gay men and more masculinized women are more vulnerable to discrimination. According to them, the acceptance of homoerotic relations between women occurs when gender expressions are closer to acceptable feminine patterns, as well as an appropriation by masculine fetish. Regarding the coping strategies, we found both forms of keeping a "discrete" identity as well as more combative ways linked to a "militant subjectification". In general, the interviewees consider contemporary times better, related more to social movements actions than the government protection apparatus.
\end{abstract}

Key words: Homophobia, Lesbophobia, Women, Human Rights, Brazil sans Homophobia.

\title{
Resumen
}

Lo objetivo de este artículo es describir y analizar las estrategias construidas por mujeres que procuraran lo Centro de Referencia en Derechos Humanos "Rompa o Silêncio" (Porto Alegre, RS) como forma de lidiar, confrontar o contestar los significados estigmatizantes asociados a sus identidades de genero o practicas eróticas/afectuosas con otras mujeres. La herramienta metodológica utilizada se baso en la entrevista de reconstrucción de las trayectorias de vida, 9 mujeres que procuraran el Centro fueran entrevistadas. La análisis se dividió en dos ejes temáticos: a) la percepción de la homofobia por parte de la mujeres; b) las formas de enfrentamiento y los significad os atribuidos para la formalización de la quejas y la 
reivindicación de derechos. Lo material de investigación permitió de comprehender que las entrevistadas ven la discriminación y el prejudicio como resultado de una extrapolación de las convenciones de género. En este sentido, perciben que los hombres gais y las mujeres masculinizadas son más vulnerables a la discriminación. De acuerdo con ellas 1 a aceptación de las prácticas homoeróticas entre mujeres ocurre en articulación con expresiones de género mas cerca de los padrones femeninos consagrados, y también cuando incorporadas por el fetiche masculino. Las estrategias de enfrentamiento van desde mantener una identidad 'discreta' asta formas más combativas próximas de una "subjetivación militante". En general, las entrevistadas consideran que es mejor vivir hoy, y que las transformaciones están más asociadas a la acción de los movimientos sociales que a las políticas publicas.

Palabras llave: Homofobia, Lesbofobia, Mujeres, Derechos Humanos, Brasil sin Homofobia

\section{Introdução}

Vivemos um momento ímpar no cenário brasileiro no que tange à luta por direitos relativos à liberdade no exercício da sexualidade. Assistimos ao desenvolvimento e implementação de políticas públicas voltadas à "população LGBTT", como é o caso do programa Brasil Sem Homofobia, lançado em 2004, assim como as Conferências Nacionais LGBT em 2008 e 2011 e seus respectivos relatórios e planos subsequentes, sem contar as ações dos governos municipais e estaduais com a criação de departamentos ou secretarias que se ocupam da diversidade sexual e do combate à discriminação ${ }^{1}$.

No campo das políticas públicas, o combate à discriminação teve como uma de suas primeiras ações a criação de Centros de Referência em Direitos
Humanos seguindo o objetivo principal do Programa Brasil sem Homofobia que é o de promover a cidadania de gays, lésbicas, travestis, transgêneros e bissexuais a partir da equiparação de direitos e do combate à discriminação e violência homofóbicas, respeitando a especificidade de cada um destes segmentos populacionais (Conselho Nacional de Combate à Discriminação, 2004). Para alcançar tal objetivo, o programa propõe a articulação de Ministérios e Secretarias em âmbito federal para a construção de ações nos campos da saúde, educação, trabalho, segurança, cultura, políticas para as mulheres, juventude e contra o racismo.

A pesquisa que apoia o presente $\operatorname{artigo}^{2}$ se situa no interior deste contexto de ações, ao buscar compreender as formas de viver o preconceito e a discriminação 
por parte de mulheres que buscaram o Centro de Referência em Direitos Humanos Rompa o Silêncio (CRDH Rompa o Silêncio), voltado ao combate e prevenção à homofobia, sediado, realizado e concebido pela ONG Nuances ${ }^{3}$ (Porto Alegre, RS) de 2006 a 2009.

O CRDH Rompa o Silêncio teve como objetivos combater as discriminações e violências de cunho homofóbico e heterossexista, bem como buscar a equiparação de direitos para a população LGBTT. Para tanto, foram desenvolvidas várias ações, tais como: acolhimento e encaminhamento das denúncias; orientação através de assistência jurídica e psicossocial; divulgação de material informativo sobre direitos e formalização de denúncias, bem como oferta de cursos de formação em Direitos Humanos e Diversidade Sexual para profissionais do direito e da saúde.

A pesquisa que deu origem a este artigo buscou, a partir dos relatos de vida de mulheres que buscaram o Centro, compreender a forma como elas têm vivenciado a violência e a discriminação homofóbica, como as têm percebido e que efeitos produziram em suas vidas. Nessa direção, busca-se descrever e analisar as estratégias construídas para lidar, enfrentar ou contestar os significados estigmatizantes associados a suas práticas eróticas/afetos com outras mulheres e/ou identidades sexuais.

O artigo, portanto, está estruturado em duas partes além desta introdução. A primeira trata da abordagem metodológica na produção do corpus da pesquisa; a segunda parte, dedicada à apresentação do material de pesquisa e sua análise, está dividida em dois eixos temáticos: a) percepções sobre a homofobia na perspectiva das mulheres e b) estratégias de enfrentamento cotidianas e o sentido da busca pela formalização da denúncia e reivindicação de direitos.

\section{O fazer da pesquisa}

A seleção das mulheres que fizeram parte deste estudo foi realizada com o auxílio da ONG Nuances contando com o consentimento institucional da ONG, bem como com o consentimento livre e esclarecido das mulheres participantes. Essas foram selecionadas a partir de uma listagem das mulheres que haviam acessado o Centro de Referência em 2007. Foi feito contato telefônico, por e-mail ou através de alguma entidade ou pessoa de referência. Após algumas semanas de tentativas, nove mulheres aceitaram participar da pesquisa.

Inicialmente a pesquisa tinha por objetivo alcançar mulheres com diferentes 
perfis de escolaridade, remuneração, cor e idade. Apesar desta prerrogativa, mulheres com escolaridade abaixo do ensino médio, ou que se declararam negras ou pardas, bem como as com idade inferior a vinte anos acabaram por não fazer parte desta pesquisa. Um número reduzido de mulheres com essas características recorreu ao serviço e não houve sucesso em estabelecer contato com elas por terem mudado de endereço ou mesmo de telefone. Ainda que o grupo composto não tenha apresentado maior diversidade nos quesitos acima mencionados, as nove entrevistadas refletem o perfil de mulheres que mais acessaram o centro naquele ano ${ }^{4}$.

Com o objetivo de manter sua privacidade, informações pessoais tais como nomes próprios foram suprimidos e substituídos por nomes fictícios. Para fins deste artigo e de forma bastante resumida, descrevemos algumas características das entrevistadas, são elas: Cláudia, 30 anos, professora da rede pública, residente em Porto Alegre; Heloísa, 42 anos, professora de educação física, residente em Porto Alegre; Imara, 44 anos, assistente administrativa, residente em Porto Alegre; Vanessa, 23 anos, estudante de Psicologia, residente em Porto Alegre; Simone, 30 anos, artesã, residente em Canoas; Vivian, 19 anos, estudante, residente em Porto Alegre; Odila, 40 anos, funcionária de uma empresa de transporte, residente em Porto Alegre; Lúcia, 26 anos, artesã, residente em porto Alegre; Patrícia, 29 anos, professora da rede pública, residente em Porto Alegre.

A ferramenta metodológica utilizada foi a entrevista baseada na reconstrução das trajetórias de vida (Cabanes, 2000; Bertaux 2003 Bueno, 2002) como meio de acessar os enunciados que evidenciam os jogos de verdade que balizam sua experiência de si (Foucault, 1998; Nardi \& Silva, 2009), a maneira como se colocam no mundo e como avaliam as formas pelas quais são interpeladas cotidianamente em suas expressões de gênero e de orientação sexual. A análise buscou compreender a rede enunciativa utilizada pelas mulheres para dar inteligibilidade aos seus relatos e que as situam no interior do diagrama de forças que configura as possibilidades de construção de si em contextos específicos de suas vidas. Desta forma é possível, através desta ferramenta de pesquisa, analisar um fragmento particular do contexto sócio histórico e compreender seu funcionamento e sua transformação, enfatizando as relações sociais, os mecanismos, os processos, as lógicas de ação que o caracterizam. Nesta perspectiva, a pessoa entrevistada é convidada a passar sua experiência por um 
filtro, na medida em que se anunciará a temática de pesquisa. Neste estudo, foi utilizada como pergunta indutora do relato e, ao mesmo tempo, como filtro que centraliza a narrativa, a seguinte questão: Como a questão do preconceito e da discriminação tem aparecido na tua vida?

Apesar de haver uma pergunta central, as entrevistas eram abertas e sem uma estrutura fixa. A ideia era deixar a entrevistada falar o mais livremente possível, pontuando, aqui e ali, questões que gostaria de abordar ou aprofundar. Por isso pareceu pertinente, no caso em que o relato não ocorresse espontaneamente, ter uma espécie de guia dos tópicos que se gostaria de abordar, sem buscar dar uma forma fixa à entrevista. Alguns destes tópicos envolviam os acontecimentos em torno do momento em que passou a interessar-se eroticamente por outras mulheres, as sensações e acontecimentos diante de seus familiares, na escola, nas relações de trabalho e de amizade.

\section{A homofobia e o heterossexismo como guardiões das fronteiras de gênero.}

$\mathrm{O}$ que um homem ou uma mulher "podem" fazer? O que "devem" sentir? Qual a maneira "correta" de expressarem seus gostos, suas preferências sexuais, seus estilos? Essas são perguntas constantemente recolocadas, principalmente quando "a pluralidade de identidades e de práticas amorosas e sexuais parece, hoje, mais visível" (Louro, 2008, p. 87). De forma mais marcante ainda, se levarmos em conta o horizonte normativo no qual estamos imersos, essas questões nos colocam frente à (in)viabilidade de determinados sujeitos e de determinadas práticas no interior de uma cena coerciva (Butler, 2004).

No caso das mulheres, a que sorte de convenções sociais estão submetidas? O que torna a vida de uma mulher mais ou menos viável no interior de uma sociedade onde a heterossexualidade é a referência? As histórias que compõem esta pesquisa falam de mulheres que romperam com aquilo que delas era esperado e que sofreram as consequências desta "transgressão". Muitas das mulheres falaram do que acreditavam ser esperado de uma mulher de "verdade", como evidenciam as falas de Cláudia e Simone:
"Porque as pessoas educam, esperam e querem conviver com os padrões sociais. Mulher tem que ser feminina, tem que usar brinco, tem que usar roupa justa, tem que usar saia, é a feminilidade padrão. E as pessoas não aceitam, o que é estranho incomoda”. (Cláudia)

"A gente é criada para ser queridinha, para ser educada, para ser meiga, para 
obedecer, pra casar e ter filhos, sabe?"

(Simone)

"Era pra eu parar de jogar futebol, guria não joga futebol, né...ou seja tu não é homem...as pessoas não aceitavam... a própria família, as outras pessoas, imagina, na própria família? E as pessoas te cobrando, porque então tu tem que casar, quando é que tu vai casar...aquelas cobranças todas, que é normal até para quem gosta de homem....só que eu cresci assim, gostando de mulher e tendo que me esconder, não tinha família pra me abrir, não tinha amigos porque tinha medo, não tinha ninguém. Na verdade era eu e eu, no meu mundo."(Imara)

As histórias dessas mulheres evidenciaram as dificuldades em se atravessar as fronteiras daquilo que é socialmente estabelecido, mais "aceito" ou reconhecido em relação aos regramentos de gênero do feminino. Considerando os caminhos que trilharam no decorrer de suas vidas e trajetórias sexuais e de gênero, ao atravessarem essas fronteiras, elas sofreram uma série de sanções. Sanções essas que lhes recolocam a questão do que é esperado de uma mulher para que se torne um sujeito mais ou menos viável, mais ou menos inteligível. É como sanção à transgressão que a homofobia se constrói, uma vez que a homofobia e a lesbofobia são mecanismos implícitos à norma (Welzer-Lang, 2001; Borrilo, 2000-2009) que reatualiza esta questão, servindo como guardiãs dos limites que a norma impõe. Vanessa aponta essas sanções ao relatar sua relação com a família:

\begin{abstract}
"No início do relacionamento minha família não sabia e era uma coisa mais escondida, mas na rua a gente andava de mão dada e tava junto sempre. A gente com o tempo foi ficando mais retraída, mais com medo. Porque tu está na rua, daí vem uns fiascos, e gritam coisas que começam a dar medo de agressões. E aí a gente começa a ouvir várias histórias de pessoas que são agredidas. Em casa também quando a minha família descobriu não foi legal. Foi bem difícil e eu acho que isso é uma coisa que fez com que eu na rua me comportasse de forma diferente. Porque a minha mãe, "ai se tu não faz isso por ti, faz por mim”. Ela sente vergonha, então eu fico pensando, bom será que eu posso fazer isso? Porque não é só eu, envolve outras pessoas que vão estar se chateando, se magoando. Então começa várias coisas que fizeram com que a gente não ficasse mais confortável na rua." (Vanessa)

"Qual é o espaço que a gente tem sabe? Porque na rua não dá, porque na rua eu já me sinto mal. Aí na minha casa não dá. Quais são os espaços que a gente tem sabe? Isso é um problema que torna bem complicada a relação, a falta de espaço." (Vanessa)
\end{abstract}

Odila, falando sobre a relação com sua filha, refere que: 


\begin{abstract}
"A minha filha fez uma carta, que eu não contei para ela, mas isso ela tinha dez anos de idade. Como ela nunca conviveu com essa situação, talvez ela não entendesse ou talvez saísse contando pra todo mundo, achando uma coisa diferente. E talvez os vizinhos da volta também pudessem tratar mal sem necessidade, porque todos já me conheciam, mas é como se fosse um filho ladrão. Descobrir que teu filho é bom, mas ele é ladrão já muda de figura.", (Odila)
\end{abstract}

Os relatos de Vanessa e Odila nos mostram o quanto a lesbofobia determina lugares e posições para uma vida ou, melhor dizendo, determina que lugar o sujeito tem dentro de um espaço já demarcado pela norma: o lugar da vergonha, da precariedade, da doença, do engodo, da trapaça,o lugar da abjeção (Butler, 2005a). Elas, assim como todas as participantes desta pesquisa, compreendem que suas sexualidades marcadas pelo desejo por outras mulheres as estigmatizam, colocando-as em posição de desvantagem nas hierarquias sociais. Ao longo de suas vidas, mesmo que nem sempre tenham se relacionado ou tido desejo sexual por outras mulheres, elas aprenderam isso. Isto porque a matriz heteronormativa a partir da qual se constituíram enquanto sujeitos de uma sexualidade (Foucault, 1998) as precede. Pois, como afirma Butler (2005b; 2004), os sujeitos se produzem e são produzidos dentro de esquemas de reconhecimento que estão presentes no contexto de seu surgimento. Apesar de o campo de possibilidades para a expressão pública da homossexualidade ser hoje mais amplo, todos e todas estão submetidos/as a regimes de verdade que permitem que certos sujeitos sejam "reconhecidos" como mais legítimos, em detrimento de outros para os quais o 'reconhecimento' ou é subtraído ou se faz pela via da abjeção (Butler, 2004). Lúcia, ao falar da relação que estabelece com sua família, refere:

\footnotetext{
"Ai ele (parente) escrachou, ele é evangélico também, a família é toda evangélica. São fanáticos. E daí ele me xingou, "sua lésbica, machorra", e eu, "mas que exemplo tu vai dar para o teu filho quando tu tiver teu filho", que ele recém tinha casado, "que exemplo tu vai dar quando tu ter um filho se tu é desse jeito". E ele falou, "E tu que nunca vai ter, sua lésbica, machorra."(Lúcia).
}

O que está em questão aqui é o reconhecimento (ou não reconhecimento) de Lúcia enquanto mulher "normal". As palavras "lésbica e machorra", utilizadas aqui como injuriosas, servem como demarcadoras de um espaço moral. Assim, quando uma mulher ouve esta palavra, ela sabe que transgrediu uma barreira. No caso de Lúcia, essa posição se encontra aqui 
mais marcada pelo fato de ela fazer parte de uma família de forte pertencimento religioso. Crença religiosa onde as posições masculinas e femininas estão profundamente atreladas aos papéis que se deve desempenhar dentro da família: a mulher mãe, submissa aos filhos e ao marido; o homem pai, provedor.

De forma geral, no entanto, as mulheres desta pesquisa percebem que o que está em questão em um ato de discriminação homofóbica é o atravessamento das convenções estabelecidas na construção da linearidade e concordância do sistema sexo-gênerosexualidade. Isto fica patente quando frases como "não aparentar" aparecem nas falas, o que demonstra que elas interpretam que quando estes atravessamentos ficam "aparentes" é que ocorre a possibilidade de serem vítimas de discriminação ou preconceito, como é possível perceber nas falas de Lúcia e Patrícia:

“É dificil a gente ser descriminada... Porque a gente não aparenta ser ... aquela hora a gente tava com afetos e carinho, de mão dada e com frescurinha, sabe?! E a gente tava vendo os cartazes, não tava nem aí naquele momento. Então quando o cara disse que a gente não podia entrar no banheiro e a Pati quis saber por quê, o cara não dizia... E as senhoras passavame entravam, então é uma situação bem constrangedora. Bem ruim mesmo."

(Lúcia)

"Fora estes dois momentos eu não sinto discriminação... talvez ... certamente porque eu não aparento, não tenho um comportamento que chocaria as pessoas. Com certeza as meninas que têm um fenótipo mais masculinizado já demonstram mais....com certeza, pelo fato de eu ser feminina, só quem conhece que sabe, nunca me vê com um namorado que pode desconfiar. E não acho isso uma coisa boa ou uma coisa ruim pra mim, sinceramente, é indiferente." (Patrícia)

As entrevistadas interpretam que aquelas mulheres que apresentam atributos corporais ou de estilo mais distanciado de um padrão feminino, e que se aproximam de padrões e estilos masculinos sofrem mais preconceito e discriminação. Como afirma Mario Pecheny (2004), a homossexualidade aparece como um segredo fundante da identidade e das relações pessoais de homossexuais; ao mesmo tempo, constitui um motivo de estigmatização e exclusão. Entretanto, salvo indivíduos que adotam marcas e trejeitos corporais, ela não é aparente aos olhos dos demais. Neste sentido, adotar um estilo que se distancie de padrões de feminilidade ou, no caso dos homens, de masculinidade, é interpretado como algo que "torna aparente" e "denuncia" a homossexualidade. Aquelas/es que não o fazem, chegam a ganhar o "benefício da 
dúvida" como comentou uma das entrevistadas. Já as mulheres "mais masculinizadas", assim como os "homens mais afeminados" tornam-se mais evidentes, portanto mais alvo de discriminações, como vemos na fala de Simone e Odila:

\begin{abstract}
"Acho que as que têm o visual mais masculino sofrem mais. Até em termos de conseguir emprego. Se a pessoa olha já está na cara que é lésbica. Então se a pessoa é mais feminina, olha, é mulher né.
\end{abstract} Agora se tu pareces mais masculina na frente das pessoas, já olha "é lésbica, não vamos contratar", já risca né, amassa o currículo e pá, põe fora. Eu sei por causa da minha companheira. Ela tem um visu mais masculino. Não gosta de ser comparada com homens, mas ela tem um visu mais masculino. E ela sofre brutalmente. (Simone)

“Os meninos são mais a vontade, são mais debochados e as meninas algumas, outras já são mais tranquilas, mais calmas. Para trabalhar eu acho os meninos se mostram mais, os homens mostram bem mais. Tu vês até aqui, tu olha de longe tu jura que ele é hetero, aí começa a falar tu vê que não é, se denuncia. E as mulheres não, é mais fácil de ficar na dúvida. É eu acho que os homens sofrem mais, eu acho que é mais difícil para eles, porque eles não têm como esconder tanto quanto a gente. Alguns até levam jeito de falar, outros não. Mas quando o amigo sabe que ele é... já deixa mais de ser tão amigo e vira colega. Se saía bastante junto, já deixa de sair. $O$ que eu já vi de coisas assim né?! E nas mulheres eu acho bem mais difícil acontecer." (Odila)

Demonstrar mais, sofrer mais; demonstrar menos, sofrer menos. Isso é o que fica evidenciado nas falas acima. A preocupação em "não aparentar", "não chocar" (Patrícia) e ficar no limite de certa "tolerabilidade" perante os outros demonstra as formas como a norma é incorporada e percebida entre algumas das entrevistadas, principalmente aquelas que se consideram mais "discretas" ou mais "femininas". Neste sentido, estar mais pra lá ou mais pra cá da norma produz diferenciações entre as mulheres com práticas homoeróticas, onde aquelas que se afastam mais são entendidas como rompendo com seu gênero, "tentando aparentar o que não se é" (como aparece nas falas de Odila e Lúcia) ou "estando num corpo errado", conforme refere/explica Patrícia. O corpo, nestas falas, aparece como sítio fundamental de onde deveria "emergir" o gênero, o qual deveria estar em consonância com este “corpo/sexo". Porém, deve-se compreender esse enunciado como fazendo parte de um discurso que assume a legitimidade de uma verdade, o qual é apropriado por parte das entrevistadas e que procura explicar a "natureza" dos fenômenos através de uma base biológica. 
Em sua pesquisa de mestrado sobre a construção e manutenção de identidades lésbicas, Rosimeri Aquino (1992) usa o termo "dar bandeira" para se referir ao receio de algumas de suas participantes em revelar uma identidade lésbica em determinados contextos sociais, pela potencialidade de se verem expostas ao preconceito. Estar "aparente", ou "dar bandeira" é também compreendido, por parte das participantes da pesquisa, como algo que as exporia à discriminação e ao preconceito, como vemos no relato de Vanessa:

\begin{abstract}
“Várias pessoas, meus amigos mais próximos, todos sabiam que eu namorava ela. A gente estava sempre mais ou menos junto. Mas quando aconteceu, até eu acho que um dos motivos de acontecer esse incidente e foi porque a gente já estava progressivamente assumindo mais, demonstrando mais publicamente". (Vanessa)
\end{abstract}

A situação de discriminação da qual fala a entrevistada se refere à uma ação violenta de um segurança que interpelou Vanessa e sua companheira por estarem namorando em local público, mais especificamente, na fila do Restaurante Universitário. A demonstração pública ou a revelação pública de uma identidade estigmatizada - "estar aparente" - é visto por grande parte das participantes como algo que as exporia à homofobia. Em contrapartida, esse "estar ou não aparente" que significa ser mais ou menos visível, é algo que elas também relacionam com as formas com as quais a lesbofobia “aparece" em suas vidas. Elas compreendem que há formas sutis de preconceito e discriminação, que nem sempre se expressam através da injúria ou da agressão física, mas antes, através de coerções, perseguições, afastamentos que nem sempre expõem claramente sua razão.

“É raro acontecer essas situações. Às vezes as pessoas até pensam coisas, mas elas não falam. É tudo assim pisando em ovos, faz de conta, tem muito faz de conta. Esse mundo é lindo e que tudo é aceito. Eu acho que isso te impede até de tu falares realmente alguma coisa. Tu pode fazer tudo, tu pode ser o que tu quiser, mas fica na tua.... As coisas ficam lá... Tudo é bonito mas cada um no seu canto. A gente não vai criticar, ninguém vai demonstrar preconceito desde que as pessoas fiquem na sua”.(Vanessa)

A maior parte dos casos denunciados ao $\mathrm{CRDH}$ revelava situações que envolviam assédio moral/psicológico $(42,5 \%)$. Este dado demonstra que existem manifestações de discriminação sutis, que também procuram "não se expor", que podem estar relacionadas ao ambiente onde ocorrem, como locais públicos, bares e instituições públicas ou o próprio ambiente 
de trabalho (como nos casos de Patrícia, Lúcia e Cláudia). Manifestações como esta indicam que, apesar de ocorrerem de forma implícita, pode existir o receio, por parte dos agressores/as, de sofrerem sanções caso as agressões sejam mais explícitas. A lesbofobia então toma a forma de uma agressão velada ou de uma constante reafirmação da heterossexualidade como norma (Heteronormatividade). Uma manifestação por vezes mascarada como "politicamente correta" (se é que se pode falar assim) que é percebida pelas entrevistadas como uma discriminação velada.

É necessário perceber as diversas formas pelas quais as expressões de gênero e da sexualidade se entrecruzam com outros conjuntos de pertencimentos dos sujeitos; estes entrecruzamentos caracterizam o lugar no qual sujeitos estão posicionados no interior dos discursos. Apoiada em Kimberley Crenshaw (2002), Vânia Oliveira (2007) propõe o conceito de interseccionalidade, evidenciando a forma como identidades sexuais se relacionam ou se articulam com outros pertencimentos produzindo intersecções que podem contribuir ou não a uma maior vulnerabilidade dos sujeitos.

O posicionamento dos sujeitos também tem efeitos nas formas como as participantes desta pesquisa vivenciam e dão sentido as manifestações de discriminação e preconceito que foram vítimas. Como já dito, todas entrevistadas são brancas, têm no mínimo o ensino médio completo e todas possuem ou uma inserção formal no mercado de trabalho, ou uma boa perspectiva de inserção profissional. Algumas delas têm um posicionamento mais próximo da militância ou, por suas inserções profissionais ou estudantis, tiveram contato mais próximo com perspectivas teóricas e políticas que desconstroem paradigmas essencialistas do gênero e da heterossexualidade.

Assim, em alguns dos casos, expressões de lesbofobia ou heterossexismo direcionadas às entrevistadas são atribuídas às diferentes manifestações de sexualidade e gênero, sem que elas relacionem estas manifestações a outros fatores, como raça/cor, classe social, entre outros. A discriminação aqui, mas também nos outros casos, produz uma identificação hiperbólica com a sexualidade que faz com que outros pertencimentos ou identificações fiquem subsumidos à identidade sexual. Em alguns casos, isso se torna razão de descontentamento. As falas de Heloísa e de Vanessa exemplificam esta questão: 
"Eles pensam na gente como um sexo e não como um ser. E a gente é um ser, a gente tem sexualidade, mas a gente é um ser humano. E eles não veem isso, eles veem a sexualidade $e$ ainda pejorativamente.” (Heloisa)

"teve um episódio que minha mãe tentou se matar e теи pai chegou em casa e a Paula estava. E aí ele mandou a Paula embora dizendo que ia chamar a polícia se ela não fosse embora. E aí depois ele disse para mim, "ah viu tua mãe tentou se matar porque tu estás com uma menina”. É difícil assim, porque eu me torno vulnerável, é motivo para as pessoas colocarem culpa." (Vanessa)

\section{A "maior aceitabilidade" das relações homoeróticas entre mulheres: mais "aceita" ou mais invisibilizada?}

“Quem é homossexual aceito?
Homossexual certinho, quietinho, que não
incomoda. Não a bicha que é
espalhafatosa e nem a bicha pobre... E a
mesma coisa das mulheres. Quem é a
lésbica aceita? Eu além de ser lésbica, me
constituir assim e me posicionar e me
assumir, eu não baixo minha cabeça."
(Claúdia)

Há um enunciado recorrente nas entrevistas que diz respeito ao fato de que todas as mulheres entrevistadas acreditavam que "a" homossexualidade feminina era mais "aceita" do que "a" homossexualidade nos homens. Que significados, ou melhor, que enunciados estão por traz desta afirmação?

Parafraseando Cláudia, que homossexualidade feminina é "aceita"? E de que forma?

O termo usado "aceitação" tem, segundo o dicionário Aurélio, 8 diferentes significados. Desses, os que mais se aproximavam às formas como as mulheres davam sentido a esta palavra são: "consentir em", "conformar-se com", “admitir, tolerar, suportar".

Alguém tolera, consente, suporta ou conforma-se com alguma coisa. Ao se tolerar, tolera-se algo que não está de acordo com os princípios da pessoa que tolera, ou algo que ela não admitiria para si. Alguém suporta uma situação ruim ou um fardo. Em todos os casos, quem "consente", "tolera", "suporta" ou "aceita" está em uma relação de assimetria no que se refere à situação, pessoa ou coisa a ser aceita, onde quem aceita determina o que deve ser aceito ou não e talvez imponha certas regras. O uso do termo é importante, pois remete às relações de poder que a perspectiva da aceitação implica, isto é, uma relação implícita com a heteronormatividade e uma reafirmação das hierarquias sexuais definindo as hierarquias das posições de sujeito.

A forma como as mulheres desta pesquisa percebiam a experiência de discriminação e preconceito remete para a 
maneira como elas qualificavam estas discriminações em comparação com outros sujeitos, como, no caso, os homens homossexuais. Os relatos abaixo explicitam essas questões e são elucidativos nesse sentido.

“Não sei, eu já pensei bastante sobre isso. Porque por um lado, eu acho que também tem muito a questão da mulher mesmo sofrer mais preconceitos. Só por tu já ser mulher vai sofrer mais preconceito. Ao mesmo tempo tem essa coisa dos homens em geral assim tolerarem mais mulheres homossexuais do que homens homossexuais. Eu estou pensando na minha situação, porque eu acho que com as meninas mais masculinizadas o negócio é mais difícil. Daí de repente a aceitação é bem menor." (Vanessa)

“Com certeza os olhares das pessoas... é brutal, mas quanto a nós, mulheres, é mais aceitável perante a sociedade do que os homens. Se sai um casal de gay no meio da rua é capaz de ser espancado. Nós não, as mulheres é mais aceitável. Mas eu acho que é machismo. Porque duas mulheres eles acham bonito. Se eles pudessem, eles até estavam no meio. A gente até é privilegiada porque para a mulher eles falam pelas costas." (Simone)

Após a leitura das falas de Simone e de Vanessa, cabe-nos indagar o que faz com que elas entendam que a homossexualidade feminina é "mais aceita". Uma primeira pergunta talvez seja: quem aceita? Uma segunda: aceita quem? Podemos encontrar a resposta para essas perguntas nas duas falas: homens heterossexuais e mulheres homossexuais com o estilo mais próximo do feminino padrão. E será que são aceitas? Segundo o relato de Simone, poderíamos dizer que elas são até mesmo desejadas.

Para Denise Portinari (1989), o silêncio em torno das homossexualidades femininas só toma sentido quando contrastado com o ruído que as homossexualidades masculinas produzem. Podemos relacionar esta ausência de ruído de certas perfomances homossexuais femininas a sua colagem em uma performance de gênero mais próxima do feminino padrão. Ao adotarem um estilo mais próximo do feminino, podem se tornar mais "invisíveis". Guacira Louro (2001; 2005) aponta que, em nosso contexto social, a homossexualidade feminina pode ser menos percebida, pois, em nossa cultura, as expressões afetivas entre mulheres parecem possuir um leque mais amplo que as relações entre homens. Trocas de carinho, de confidências e até mesmo a possibilidade de amigas dormirem juntas, de alguma forma, podem borrar os limites entre a simples amizade e a relação amorosa. Falar em "homossexualidade feminina", no entanto, pode também borrar uma infinidade de 
performances e estilos que não necessariamente se encaixam em um modelo único.

Segundo Jaqueline Muniz (1992), existe uma dificuldade de colocar as homossexualidades femininas (em todas as suas variantes e performances de gênero) em discurso; de forma geral, esta experiência se fixou no imaginário dominante em torno da figura da lésbica masculinizada, da caminhoneira, da sapatão. Pode-se afirmar que estas designações se fazem presentes e se reatualizam no cotidiano no qual as mulheres desta pesquisa se inserem. No entanto, basta ligar a televisão a cabo e passear por canais ditos "adultos", como a Playboy TV, para encontrar cenas bastante eróticas entre mulheres, todas elas femininas, lindas e "saradas". Práticas homoeróticas entre mulheres povoam o imaginário erótico masculino.

“Uma reclamação que eu tenho, acho que a Paula também, é dos homens se aproximarem e achar que não precisa respeitar uma relação de casal porque são duas mulheres. Quer dizer, se fosse uma mulher com um namorado, se fosse um casal heterossexual, não ia chegar o homem e dar em cima na frente da outra. E eu acho que embora não tenha um preconceito em relação à pessoa, não tem o reconhecimento." (Vanessa)
Nesse mesmo sentido, para Carmen Oliveira (2002) e Tânia Swain (2007), cenas de sexo entre mulheres são bastante utilizadas para gerar a excitação masculina. Dessa forma, as relações homoeróticas entre mulheres são frequentemente vistas mais como uma forma de seduzir os homens do que como uma prática que não os requeira ou não os diga respeito, uma vez que o script padrão dos filmes eróticos inicia com uma cena de carícias entre mulheres, mas termina com a chegada do homem e a penetração. Assim, o que aparece é que a norma heterossexual/sexista apropria-se do erotismo homossexual feminino, esvaziando-o de sentido para torná-lo mais um elemento do fetiche masculino. Neste caso, talvez a melhor palavra não fosse "invisibilidade"; talvez fosse mais interessante indagar que tipos de visibilidade as relações homoeróticas entre mulheres tomam, pois neste caso as homossexualidades femininas podem até ser visibilizadas, porém sendo "obscurecidas ou negadas enquanto prática ligada ao humano" (Swain, 2007, p. 10).

Portanto, "aceitar" aqui significa estar submetida aos esquemas de compreensão de um pensamento heterocentrado. É possível evocar aqui o trabalho de Monique Wittig (1992) sobre o "pensamento heterossexual". Para ela, a 
sociedade heteronormativa desenvolveu uma interpretação totalizante da cultura e da história. Segundo a autora, o pensamento hetero não consegue conceber uma cultura onde a heterossexualidade não ordene as relações humanas e a produção de sentidos. Assim, segundo ela "para o pensamento heterossexual, a homossexualidade não passa de heterossexualidade" (Wittig, 1992, P.28).

"Mas de uma maneira geral eu acho que os homossexuais masculinos sofrem mais do que as mulheres. As mulheres também têm mais aquela questão do sentimento "duas mulheres... pode ser uma fase", e os homens acham bonito, interessante, gostam. Mas com homens, isso mexe com o machismo, que é bem forte aqui." (Patrícia)

É claro que muitas mulheres podem adotar identidades mais fluidas, que podem ser expressas pela fórmula "ser ou estar homossexual" (Heilborn, 1996). No entanto, "poder ser uma fase" evoca também a apropriação e domesticação da sexualidade feminina. Segundo Foucault (1998), um dos domínios através dos quais o dispositivo da sexualidade se instalou no final do século XVIII foi na "histerização do corpo da mulher". Um corpo revistado, "qualificado e desqualificado como corpo saturado de sexualidade, pela qual este corpo foi integrado sob o efeito de uma patologia que lhe seria intrínseca" (Foucault, 1998, p. 99). Um corpo "transbordante" de uma sexualidade não direcionada que deveria ser avaliado e adestrado. Ao realizar estudos históricos referentes à emergência da sexologia, Jonathan Katz (1996) argumenta que antes de sua fixação em categorias distintas de sujeitos, as práticas que hoje são associadas à homossexualidade e à heterossexualidade eram descritas como "excessos sexuais". Nesse sentido, a mulher era qualificada como possuindo uma natureza "menos heterossexual", portanto mais suscetível a "deslizes".

Dessa forma, alguns relatos apontam para uma especificidade no preconceito e discriminação vivenciados pelas mulheres entrevistadas: a tentativa de subordinação de suas expressões sexuais ao erotismo masculino e sua consequente invisibilização como uma forma legítima de expressão.

Mas estar "invisível", do modo aqui descrito é necessariamente uma desvantagem? Como diz Judith Butler (2004), os esquemas de reconhecimento disponíveis podem desconstruir alguém tanto em um ato de reconhecimento como na sua negação. Nesse ponto, estar ou não visível, receber ou não "reconhecimento", remete a relações de poder através das 
quais o "humano" é diferencialmente produzido.

\section{Do "armário" à "armadura"}

Quais as estratégias utilizadas pelas mulheres desta pesquisa como forma de "driblar" o estigma relacionado à sua sexualidade? Evocar as figuras do "armário" e da "armadura" para descrever as estratégias de enfrentamento do preconceito remete a dois momentos na vida dessas mulheres: antes e depois do encontro com a política pública de proteção aos direitos relacionados à sexualidade. Essas estratégias vão desde a proteção por um "manto de invisibilidade" associado a uma atitude discreta, até a adoção de uma postura mais combativa, evidenciada na decisão e possibilidade de "bancar o seu lugar" diante dos conflitos familiares e na colagem ao que poderíamos chamar de uma "subjetivação militante". É importante esclarecer que essas estratégias não são apenas criadas individualmente, mas fazem parte de um repertório ao qual essas mulheres podem recorrer dependendo de como se posicionam frente à sua sexualidade e da situação em questão.

\section{Discrições: silêncio, segredo e dissimulação.}

\begin{abstract}
"Então eu sempre tive esse medo da rejeição, daí resolvi casar e depois tive filhos pelo fato da aparência. Que nem acontece hoje, muitos casais "se fazem", ficam um com outro pra manter a aparência. "(Imara)
\end{abstract}

Manter as aparências, dissimular: tudo isso faz parte de um repertório de estratégias motivadas pelo medo ou evitação da discriminação. Algumas das entrevistadas utilizam-se do silenciamento, evitando falar sobre o assunto. Outras chegam a impor o segredo para suas parceiras; outras ainda inventam situações que produzem um simulacro de relação heterossexual. Essas estratégias, já bem descritas nos estudos das homossexualidades (Eribon, 1999; Pecheney, 2004), acabam por criar a sensação de se estar vivendo em dois mundos, pois em alguns espaços é possível falar e demonstrar afeto e, em outros, sente-se a necessidade de se tornar invisível.

“E eu tenho duas irmãs adolescentes. Uma tem 18 e a outra tem 15 anos. Eu nem sei o que fazer, porque elas estão querendo vir morar aqui. Eu não sei ainda, eu acho que eu vou ter que contar para ela. Não vai ter como esconder tanto tempo, não sei, ela vai ter que guardar 
segredo, porque eu tenho medo da reação do meu pai." (Lúcia)

"Eu disse assim: "olha eu realmente não fico falando aos quatro ventos que eu gosto de mulher”. Eu não preciso fazer isso, mesmo porque existe a discriminação, né, então imagina eu lá dentro da turma e os meus colegas veem que eu gosto de mulher, eles vão ficar chocados no mínimo. Por exemplo, no meu ambiente de trabalho, de forma alguma eu vou estar fazendo gestos, qualquer coisa em relação a isso....(Imara)"

\section{Como afirma Mario Pecheney} (2004), em uma cultura dominada pelos binarismos e pela naturalização da heterossexualidade, a homossexualidade torna-se um segredo que funda as formas com as quais homossexuais se relacionam com os outros e com os espaços. A figura do armário é emblemática neste sentido (Britzman, 1996), pois ela se relaciona ao aprendizado, por parte de homossexuais, de estratégias com as quais esconder os significantes da homossexualidade diante da intolerância e, ao mesmo tempo, de como fazê-los notados por quem se tem interesse ou que participa da mesma rede de significados. Cria-se então a possibilidade de revelação através de pessoas que "se entendem", como aparece nos relatos a seguir:

\footnotetext{
“Tu acha que as pessoas no meu trabalho sabem que eu sou gay? Aliás, duas pessoas
}

sabem: a minha supervisora e a secretária que, aliás, ela largou do marido pra ficar com a secretária. E agora elas são minhas amigas e a gente "se entende", até por que está tudo no mesmo saco, né? Mas as pessoas não sabem. Mas se me perguntam “ah, e o namorado? Não vai casar?” Eu digo "não, não tenho namorado, não vou casar". Até um dia a diretora perguntou "o que tu prefere: casar primeiro, ou ter filho primeiro?" Eu disse "precisa escolher isso? Prefiro então ter filho primeiro”. Mas eu não... Eu sou covarde neste sentido, entende, de me assumir... Não teve nenhuma oportunidade ainda, não se tocou no assunto - mas eu também, a minha aparência - por que eu me considero uma mulher feminina e também as pessoas de fora não diriam se não me conhecem. E como nesse ambiente de trabalho são só quatro horas por dia, então tu entra numa sala de aula, e tu vê o pessoal só quinze minutos no intervalo, então não tem uma relação mais duradoura. Então eu sou enrustida no ambiente de trabalho." (Patrícia)

“Eu prefiro me manter assim: se ninguém me perguntar, não digo nada. Aqui no meu trabalho ninguém sabe, só uma menina." (Odila)

Os relatos apontam para os medos e receios que a articulação entre a revelação ou não da homossexualidade e o trabalho produz para as entrevistadas. O medo da deterioração das relações de trabalho, ou mesmo, da demissão, faz com que essas mulheres usem de recursos como a 
dissimulação ou beneficiem-se de uma "heterossexualidade presumida" (Aquino, 1992; Meinerz, 2005).

Entretanto, esse esforço de controle das situações de vida, a divisão de amigos/as entre aqueles/as que podem saber e aqueles/as que não, as invenções de estratégias para evitar o assunto, as respostas evasivas, os segredos que têm que manter uma coerência no tempo demandam uma energia psíquica intensa. A incorporação na norma pela via do assujeitamento apaixonado descrito por Judith Butler (1997) pode ajudar a entender falas que revelam um sentimento incorporado de ilegitimidade do afeto e do desejo homossexual.

“A gente evita um pouco... Acho que por isso mesmo. É, esse negócio de mão dada, beijo e abraço. É mais como se fosse amiga mesmo. Em locais gays sim, daí tá liberado né.” (Lúcia)

"Eu sou uma pessoa discreta. Eu me considero, pelo menos. Eu não tenho necessidade de sair na rua de mão dada e ficar beijando. Claro, tem situações, no cinema, alguma coisa assim, ou num bar mesmo, num lugar hetero, que tu gostarias de estar mais próxima da pessoa, de beijar, enfim, de ficar mais a vontade...Mas eu naturalmente não tenho esta necessidade de que saibam que eu sou gay....mas confesso que se tivessem rumores, alguma coisa, eu não negaria, mas eu ficaria em cima do muro, entende? Eu não negaria “não eu não sou” mas também não diria 'sim, eu sou'. Porque negar alguma coisa assim eu nunca neguei, sabe? Mas também fiquei em cima do muro. Se alguém me perguntasse e eu dissesse não, seria uma coisa que me faria me sentir tão covarde, mas tão covarde... É mais do que ficar em cima do muro. Seria me agredir, então..." (Patricia)

\section{"Bancando o meu lugar"}

Outras estratégias fazem parte do enfrentamento do preconceito. Sair de casa cedo e garantir uma autonomia financeira se impõe como necessidade imediata, uma vez que a família costuma ser um primeiros agenciadores da discriminação (Eribon, 1999).

“E eu me mantenho com o meu dinheiro, sempre foi assim. Aí meu pai ficou um mês lá em casa, porque ele não estava recebendo aposentadoria. Então eu tava sustentando ele, e quando ele passou a pegar dinheiro, ele achou que eu não deveria mais ficar lá. Disse: se tu queres ter mulher tu vai dar casa para mulher, não vai? ser na minha casa que tu vai ter mulher. Eu disse: 'Não tem problema. Apesar de eu ser mulher eu sou macho suficiente para bancar minhas coisas $e$ quem está comigo, se for preciso' e fui embora. Eu tava muito a fim de ir embora para São Leopoldo, porque o salário era muito baixo e eu não conseguia me manter, eu pesava $70 \mathrm{~kg}$ e baixei pra 55 kg. Mas vivia feliz, não tinha ninguém me 
incomodando, pelo menos eu podia bancar

o meu lugar. ”(Odila)

"Ai quando eu voltei do Chile a minha mãe mandou a Agnes embora e me disse na cara: 'Oh, daqui a trinta dias, de novo, nós estamos indo embora para Caxias.' Respondi: 'Sinto muito, a senhora já fez uma vez isso comigo. Duas a senhora não vai fazer. Eu tenho dezoito anos, a senhora vai para Caxias, só me avisa uma semana antes que eu vou tirar minhas coisas.' E aí eu $e$ a Agnes alugamos um apartamento.Tudo aconteceu assim. E desde aí eu fui independente, desde os meus dezoito anos". (Heloisa)

"Eu estava pronta para fugir, nem a Heloísa sabia. Quando a gente saiu ela disse: 'Amor, para onde é que tu vai?' Eu disse 'Para onde tu quiser me levar.' Ela disse 'Por que?' 'Porque eu briguei na minha casa e olha aqui minha mochila. Para a casa eu não volto mais.' Desde aquele dia eu não voltei nunca mais." (Vivian)

No entanto, "bancar o seu lugar" exige que existam possibilidades para tal, e entre estas possibilidades deve-se incluir a de encontrar um trabalho que forneça, ao menos, mínimas condições financeiras ou, como no caso de Vivian, alguém que sirva de suporte para isso. Essa estratégia, assim como as outras, só se torna viável mediante determinadas condições. Nesse caso, fatores como classe social, nível de escolaridade, pertencimento étnico/racial podem entrar em jogo.

\section{“Sou lésbica, e daí?": modos militantes de enfrentamento}

Outra forma de construir uma vida viável é enfrentar de forma politicamente explícita o preconceito e a discriminação. Essas formas de viver abertamente a sexualidade passam, no caso de algumas entrevistadas, por um engajamento militante que não necessariamente é organizado, mas significa assumir uma forma de vida que implica em uma determinada forma de visão de mundo e projeto de sociedade. Essas estratégias por vezes são partilhadas e não exclusivas, em alguns momentos se alternam, optando pelo silenciamento e/ou pela abertura em momentos distintos da vida e/ou diferentes contextos de trabalho. A vida militante, para essas mulheres, seja de forma organizada ou como um estilo de vida, parece fornecer mais força para $o$ enfrentamento cotidiano do preconceito, pois o vínculo a uma ideia coletiva produz menos solidão nessa caminhada. É claro que esse modelo não vale para todas e cada uma encontra formas distintas de viver uma vida possível.

\footnotetext{
"sempre deixei claro para elas que eu era lésbica, que eu sou lésbica, estava na ficha funcional, nunca omiti. Na época eu tinha uma companheira e que também trabalhava no município e depois saiu. E
} 
que muitas pessoas conheciam, enfim. E pelo menos nesse espaço com as minhas colegas de profissão eu me assumo. Em relação às crianças, se chegam e perguntam se eu sou, o que até hoje não perguntaram, mas eu responderia. Para as mais próximas lá, de tanto me perguntarem, um dia eu cheguei e disse, não eu não tenho namorado eu tenho namorada. Mas é por exemplo, em conselhos de classe, daquelas velhas conversas, daquelas velhas piadinhas, como por exemplo, uma vez levantaram que uma menina estava com problemas de aprendizagem e um professor chegou $e$ falou, ah ela está com namorada. E aí continuaram meio que argumentando $e$ dando a entender que bom, estava explicado que ela estava com problema de aprendizagem porque ela estava com namorada. E comigo ali. E daí eu problematizei, que gostaria de saber se tem algum problema de ela estar namorando outra menina. Porque isso não tem nada a ver com problema de aprendizagem. Por que vocês não questionaram outros casais aqui na escola, casais hetero?" (Cláudia)

Apesar de Cláudia não participar formalmente de algum grupo de militância, sua aproximação de temas relacionados às relações entre gênero e sexualidade no período de faculdade e através de cursos de formação na área (frequentou, inclusive, um curso oferecido pelo Nuances) ajudaram-na a se posicionar de forma combativa frente à imposição da heterossexualidade como uma obrigação a todos os sujeitos. Contestando a atitude de colegas que colocavam a homossexualidade como um "problema" que poderia estar afetando a aprendizagem de uma aluna, ela problematiza e procura desestabilizar o argumento de seus colegas. Já Simone, explicita sua posição ao recusar esconder demonstrações de afeto em público.

\begin{abstract}
“A gente não esconde para ninguém. Se é para andar de mãos dadas a gente anda, não tem problemas. Até porque eu cresci aqui, todo mundo me conhece. Então ninguém, até podem falar pelas costas. Mas diretamente nunca, aqui pelo menos, nunca ninguém falou diretamente. Até sei de algumas coisas, sabe, mas coisas pequenas, então nem dou bola. Meus parentes mesmo, sabe? Tem um primo meu que mora aqui que é totalmente homofóbico. Tem a irmã dele que ela é lésbica, só que ela se esconde. E eu já cheguei abalando assim e eles levaram um baque. Porque até então eu era casada com homem. Eu sempre minha vida inteira, desde que eu me conheço por gente assim, eu sempre lutei contra o preconceito, por ser punk, por estar no meio do pessoal anarquista e coisa e tal, então eu sempre, eu nunca tive preconceito contra isso." (Simone)
\end{abstract}

Um posicionamento vigilante, desnaturalizando o cotidiano marcado pela 
homofobia e lesbofobia, passa a compor a forma de inserção profissional de Cláudia.

“Então, uma série de coisa que antes eu ficava calada e que hoje eu me posiciono mesmo que seja na brincadeira. É uma construção histórica mesmo, uma reafirmação dia-a-dia. Vem um curso do Educando, que o primeiro eu não pude participar porque eu estava em Sapiranga. $E$ isso vai te encorajando. $E$ tu vai pensando, eu vou pensando que as coisas se tornam mais fáceis. "(Cláudia)

Podemos ver aqui a emergência de uma subjetivação mais militante. Parte desse engajamento passa por estratégias de reversão do estigma, apropriando-se de termos utilizados para insultar e os transformando em palavras de afirmação positiva. Essa também foi uma das estratégias que parte do movimento homossexual e de mulheres lésbicas encontrou para buscar a afirmação de uma identidade positiva, isto é, esvaziar o sentido abjeto dos termos usados para acusação e imposição de limites ao humano e ressignificá-los de forma a produzir a afirmação de uma diferença e de um "orgulho". Como nas palavras de Simone:

\footnotetext{
“Eu não me agrido se a pessoa diz 'ah sua sapatona'. Sou mesmo! Eu não me ofendo se me chamar de machorra, sapatona,
}

lésbica. Dai eu gritei 'Sou sapatona mesmo. E aí, qual é que é? '," (Simone)

\section{“Hoje em dia é melhor": o possível, mas difícil encontro com os aparelhos de proteção do Estado.}

Não tinha a Nuances na minha época para
poder me proteger, para eu poder
conversar. (Heloisa)
É unânime entre as entrevistadas que a vida é melhor hoje que no passado. A ideia de uma vida afetiva e sexual feliz entre mulheres está no horizonte das possibilidades contemporâneas. A discriminação ainda é generalizada, mas existe uma visibilidade crescente na cultura (mídia, leis, ONGs, etc.), a qual também se materializa em alguns aparelhos do Estado. A noção de direitos ainda é difusa e pouco conhecida, mas existe uma perspectiva presente de possibilidade de proteção do Estado. A forma de fazer valer estes direitos, entretanto, ainda passa pela boa vontade de servidores mais sensíveis à questão (como no caso da delegacia da mulher e da Delegacia Regional do Trabalho) e ao conhecimento dos caminhos a trilhar para acionar a máquina do Estado.

O próprio acesso ao $\mathrm{CRDH}$ foi, na maioria dos casos, precedido do recurso à delegacia de polícia (em alguns casos à delegacia da mulher). Isso demonstra a 
precedência das políticas de promoção/proteção dos direitos humanos que primeiramente foram dirigidas às relações de gênero (pensando em uma mulher heterossexual vítima de um homem) e somente muito recentemente às questões relativas à diversidade sexual. No caso desta pesquisa, as entrevistadas não identificavam claramente uma política pública e sim a atuação protetiva da ONG nuances. Pode-se atribuir esta invisibilidade da política a certa 'timidez' governamental em assumir uma postura mais clara na mídia na defesa dos direitos das minorias sexuais, como faz com relação às mulheres (isso diz também da dificuldade de aprovar no congresso devido à resistência de deputados/as ligados à bancada religiosa - de leis que criminalizem a homofobia e que equiparem direitos). A ideia difusa de direitos se relaciona a sua recente implantação no Brasil (como no restante dos países ocidentais) e das dificuldades políticas de sustentar estas transformações face à resistência moral presente na cultura.

“Eu acho que a aproximação assim com o Nuances e com tudo o que o Nuances vem proporcionando todos esses anos. Tu ir para uma parada livre, tu começar, por exemplo, a sair para uma boate, porque eu, por exemplo, a primeira vez que eu fui numa boate, que eu decidi ir, é sempre aquela dúvida, mais o que eu vou encontrar lá? Será que vou encontrar alguém conhecido, será que eu vou encontrar alguém que eu trabalho, será que eu vou encontrar uma pessoa que eu não sei se é, como vai ser? E daí tu vai construindo até chegar nesse ponto. Então, uma série de coisas que antes eu ficava calada e que hoje eu me posiciono mesmo que seja na brincadeira. É uma construção histórica mesmo, uma reafirmação dia-adia. Vem um curso do Educando, que o primeiro eu não pude participar. E isso vai te encorajando. E tu vai pensando, eu vou pensando que as coisas se tornam mais fáceis." (Cláudia)

"Não, não foram porque tinham medo, como elas eram menores, acabava sendo chamado um dos responsáveis, aí. Que aliás, eu acho que nisso tem um despreparo muito grande no conselho tutelar e do menor e do adolescente. Porque tem adolescente que já é homossexual, que já tem sua definição, não existe uma visão de apoio ou pelo menos de apaziguar aquela situação. Bem pelo contrário, tem uma coisa assim que é repressora. E aí deixa a pessoa mais insegura e deixa na bobagem de fazer qualquer coisa. Eu acho que deveria ter pessoas mais preparadas.(Heloísa)”,

“Eu até pensei em colocar a Empresa na justiça por aceitar pessoas homofóbicas, mas hoje não tem uma lei que protege a gente. Até podemos, digamos, processar pessoas por preconceito né, mas não contra a homofobia. Não tem uma lei ainda. (Simone)"

"Por que eu na verdade assim oh, eu pensava em ir a algum lugar, mas não sabia aonde, daí a minha namorada é 
quem disse, "então tu vai a Nuance porque que lá eles têm advogados tem tudo que tu precisar eles vão te ajudar, se eles não tiverem eles vão te encaminhar, vai lá e tenta, não custa”. Porque é quem poderia me defender, por que acho que, não que os advogados de fora dali não quisessem me defender, mas eu acho que através dali, quem tá ali dentro, quem tá dentro do Nuances é pra ajudar mesmo quem é do meio, então por isso que eu fui ali. "... eu fui à delegacia, eu tenho cinco ocorrências contra essa senhora. Antes de ir pro Nuances!(Odila)

“É, me xingaram, mas não... Que nem eu te digo, me xingaram no sentido, não me chamando de alguma coisa, porque hoje em dia todo mundo sabe que eu posso te processar se tu...ousar ter algum preconceito em relação a minha pessoa, então eles tomavam muito cuidado, mas a gente sabia que nas entrelinhas era essa a causa. (Imara)

\section{A guisa de conclusão}

Muito mais teria a ser dito sobre as trajetórias destas mulheres e é claro que toda escrita comporta limites de tempo e de análise. Esta pesquisa analisa relatos que falam de um momento de transição no campo das políticas públicas. Momento esse marcado por uma primeira tentativa de transformação das ações do Estado a partir de um jogo estratégico arriscado que marcou a relação com os movimentos sociais. Estas transformações são visíveis no plano institucional, pois se o Estado durante o século XX buscou classificar, discriminar, esquadrinhar e patologizar comportamentos e desejos; vislumbramos neste início de novo século um movimento ainda tímido, de ampliação das possibilidades de viver com maior liberdade a diversidade de expressões que compõe o espectro da sexualidade.

A rede enunciativa característica do campo político institucional que se construiu nas transformações dos jogos de verdade que marcam o dispositivo da sexualidade, disputam hoje legitimidade propondo outras formas de pensar ações e programas que escapem minimamente das lógicas classificatórias e normalizadoras, embora exista sempre o risco de novas normalizações e hierarquias. Com este alerta em mente e a partir da análise enunciativa das diretrizes políticas dos movimentos sociais, fica claro que esses optaram majoritariamente por políticas identitárias, o que pode produzir novas capturas assujeitadoras a partir de definições restritivas das possibilidades de expressão do gênero e da sexualidade. Encontramos aqui o dilema apontado por Judith Butler (2004), ou seja, ao mesmo tempo em que esta estratégia produz um lócus de reconhecimento social que permite uma existência pública para além da esfera exclusiva da abjeção e do insulto, 
ela também pode criar um outro campo moral no interior da chamada "diversidade sexual", como já anunciava Gayle Rubin (1984).

\section{Notas}

${ }^{1}$ Este movimento político que aponta para a conquista de direitos igualitários produziu uma reação conservadora importante, principalmente veiculada pela bancada evangélica no Congresso Nacional e seus representantes nos estados e municípios. Esta reação se tornou mais visível e ativa após a decisão histórica do Supremo Tribunal Federal (STF) em equiparar as uniões estáveis de casais do mesmo sexo às uniões estáveis heterossexuais. Podemos assinalar também uma mudança de rumo do executivo nacional a partir do governo de Dilma Rousseff, cujo posicionamento em favor dos direitos igualitários à população LGBT tem sido ambivalente se comparada ao governo Lula, mudança esta particularmente visível no veto ao material pedagógico destinado ao combate à homofobia nas escolas, à sua ausência na II Conferência Nacional LGBT e na polêmica envolvendo a retirada de um vídeo realizado para o Ministério da Saúde com cenas de afeto entre rapazes da campanha de prevenção à aids no carnaval 2012.

2 A pesquisa original que deu origem ao artigo resultou na dissertação de mestrado de Luciana Fogaça Monteiro (Monteiro, 2009), bolsista CAPES, orientada por Henrique Caetano Nardi. A produção deste artigo, a partir do material da dissertação, foi feito em colaboração pelos/as três autores/as.

3 A ONG Nuances - grupo pela livre expressão sexual, fundada em 1991 e sediada em Porto Alegre, tem como objetivo defender e trabalhar pela cidadania e garantia de direitos as homossexualidades em geral - entendendose que aí podem estar incluídas diversas categorias identitárias, como expressa pela sigla LGBTT, mas podendo circunstancialmente ir além da representatividade desta sigla. Neste sentido, tem cumprido seu papel na proposição de leis, na denúncia e, muitas vezes, no acolhimento de denúncias de discriminação e a violência homofóbica por parte tanto de órgãos do Estado, como também de estabelecimentos privados e de indivíduos.

4 Nos dados dos usuári@s do CRDH compilados para o ano de 2007, as mulheres homossexuais ou bissexuais perfizeram um total de $25,3 \%$ do total de usuári@s. Dentre estas, 66,7\% se autoidentificavam como lésbicas, 14,3\% como bissexual, 14, 3\% como homossexual e $4,8 \%$ como gay. A grande maioria residia em Porto Alegre (71.4\%), o restante 
residindo na grande Porto Alegre (19\%) ou interior do estado $(9,5 \%)$. Quanto à idade, $47.4 \%$ estavam entre os 20 e os 30 anos; $21,1 \%$ entre 15 e 20 anos; mulheres entre 30 e 40 anos perfizeram um total de $15,8 \%$, bem como as acima de 40 anos $(15,8 \%)$. No quesito raça/etnia, a grande maioria das usuárias se considerou branca $(76,5 \%)$, sendo que pardas $11,8 \%$ e negras $11,8 \%$. No item escolaridade, $42,1 \%$ possuíam o ensino médio completo, $26,3 \%$ tinham ensino superior incompleto, 10,5\% tinham ensino superior completo, $10,5 \%$ tinham pós-graduação, 5,3\% tinham ensino fundamental completo e 5,3\% ensino fundamental incompleto.

\section{Referências}

Aquino, L. Rosimeri. (1992) As Derivas do Desejo: processos de construção, manutenção e manipulação de identidades lésbicas em um conjunto de mulheres em Porto Alegre. Dissertação (Mestrado em Antropologia Social). Universidade Federal do Rio Grande do Sul, Porto Alegre.

Borrillo, Daniel. (2000) L'homophobie. Paris: Presses Universitaires de France.

A

Homofobia. In: LIONÇO, Tatiana.; DINIZ, Débora. (Org). Homofobia e
Educação: um desafio ao silêncio. (p. 15-46) Brasília: Letras Livres/ Ed UNB,

Britzman, Débora. (1996) O que é essa coisa chamada amor: Identidade homossexual, educação e currículo. Educação \& Realidade, vol 21 (1),196-230.

Butler, Judith. (1997)The Psychic Life of Power: theories in subjection. Standford: Standford University Press.

(2004) Undoing

Gender. New York: Routledge. - (2005a) Cuerpos que importan: sobre los limites materiales y discursivos del "sexo". Buenos Aires: Paidós, 2005a. . (2005b) Giving an Account of Oneself. New York: Fordham University Press.

Conselho nacional de combate à discriminação. (2004) Brasil sem Homofobia: Programa de combate à violência e a discriminação contra GLBT e de promoção à cidadania homossexual. Brasília, Ministério da Saúde.

Crenshaw. Kimberley. (2002) Documento para o encontro de especialistas em aspectos da discriminação racial relativo ao gênero. Revista Estudos Feministas 10(1), 171-188. 
Eribon, Didier. (1999) Réflexions sur la question gay. Paris: Fayard.

Foucault, Michel. (1998) A história da Sexualidade I - A vontade de saber. $14^{\mathrm{a}}$ ed. Rio de Janeiro: Graal.

Gross, L; Woods, J. (1999) Columbia Reader on Lesbian and Gay men in Media Society and Politics. New York: Columbia University Press.

Heilborn, Maria. Luisa. (1996) "Ser ou estar homossexual: dilemas de construção de identidade social". In: Parker, Richard; Barbosa, Regina Maria (Orgs.). Sexualidades brasileiras. (p. 136-145) Rio de Janeiro: Relume Dumará/ABIAIMS-UERJ.

Katz, Jonathan Ned. (1996) A invenção da Heterossexualidade. Rio de Janeiro: Ediouro.

Louro, Guacira L. (2001) Pedagogias da Sexualidade. In LOURO, G, L (org.) O Corpo Educado: Pedagogias da Sexualidade. (p. 9-34). Belo Horizonte, Autêntica..

Heteronormatividade e homofobia.

Trabalho apresentado no I Simpósio Paraná-São Paulo de Sexualidade e Educação Sexual. Araraquara, Brasil. (2008) Cinema e

Sexualidade. Educação e Realidade, 33(1) 81-98.
Meinerz, N. E. (2005) Entre mulheres: estudo etnográfico sobre a constituição da parceria homoerótica feminina em segmentos médios na cidade de Porto Alegre-RS. Dissertação (Mestrado em Antropologia Social), IFCH, UFRGS, Porto Alegre.

Muniz, J. (1992) Mulher com mulher dá jacaré: Uma abordagem antropológica da homossexualidade feminina. Dissertação de Mestrado. Programa de Pós-Graduação em Antropologia Social, Museu Nacional, UFRJ.

Nardi, Henrique C. \& Silva, Rosane Neves (2009). Ética e Subjetivação: as técnicas de si e os jogos de verdade contemporâneos. In: Neuza Maria de Fátima Guareschi; Simone Maria Huning. (Org.). Foucault $e \quad a$ Psicologia. 1 ed. (p. 143-158) Porto Alegre: EDIPUCRS

Pecheny, Mario. (2004) Identidades Indiscretas. In: RIOS, Luis F. et al. Homossexualidade: produção cultural, cidadania e saúde. (p. 1633). Rio de Janeiro: ABIA.

Portinari, Denise. (1988) O Discurso sobre a homossexualidade feminina. Dissertação de Mestrado. PUC-RJ. Oliveira, Carmen. (2002) O Exílio do Homoerotismo feminino. In: Golin, 
Célio (org.) Homossexualidades, Política e Cultura. Porto Alegre: Sulina.

Oliveira, Vanilda Maria de. (2007) Identidades interseccionais e militâncias políticas. In: GROSSI, Miriam (org.). Conjugalidades, Parentalidades e Identidades Lésbicas, Gays e Travestis. (p. 385403) Rio de Janeiro: Garamond.

Rubin, Gayle. (1984). Thinking Sex: notes for a radical theory of the politic of sexuality. In VANCE, Carol. Pleasure and Danger. (p. 217-319) Boston: Routledge.

Swain, Tânia N. (2007) Lesbianismos, cartografia de uma interrogação. In: RIBEIRO, Paula R. C. et al (Orgs). Corpo, Gênero e Sexualidade. (p. 917) Rio Grande: Editora da FURG.

Welzer-Lang, Daniel. (2001) A construção do Masculino: a dominação das mulheres e homofobia. Rev. Estud. Fem. 9(2), 460-482.

Wittig, Monique. (1992) The Straight mind and other essays. Boston: Beacon

\footnotetext{
Luciana Fogaça Monteiro: Psicóloga, Mestre em Psicologia Social e Institucional pela UFRGS, pesquisadora associada do NUPSEX - UFRGS.
}

Paula Sandrine Machado: Psicóloga, Mestre e Doutora em Antropologia Social pela UFRGS, Professora do Departamento de Psicologia Social e Institucional e Professora do PPG em Antropologia Social da UFRGS, CoCoordenadora do NUPSEX-UFRGS.

Henrique Caetano Nardi: Médico, Mestre e Doutor em Sociologia pela UFRGS, Pós Doutor pela EHESSParis, Professor do Departamento e PPG em Psicologia Social e Institucional da UFRGS, Coordenador do NUPSEX-UFRGS.

Endereço: Rua Ramiro Barcelos 2600, CEP 90035-003, Porto Alegre, RS.

E-mail: lu_moa@yahoo.com 